(1)

\title{
Professional development initiatives for university teachers: Variables that influence the transfer of learning to the workplace
}

\section{Christian Jaramillo-Baquerizo, Martin Valcke \& Ruben Vanderlinde}

To cite this article: Christian Jaramillo-Baquerizo, Martin Valcke \& Ruben Vanderlinde (2018):

Professional development initiatives for university teachers: Variables that influence the transfer of learning to the workplace, Innovations in Education and Teaching International, DOI: 10.1080/14703297.2018.1479283

To link to this article: https://doi.org/10.1080/14703297.2018.1479283

\section{Published online: 28 May 2018.}

\section{Submit your article to this journal $\square$}

Q View related articles $\widetilde{ }$

View Crossmark data \lceil 


\title{
Professional development initiatives for university teachers: Variables that influence the transfer of learning to the workplace
}

\author{
Christian Jaramillo-Baquerizo a,b (D), Martin Valcke ${ }^{a}$ (D) and Ruben Vanderlinde ${ }^{a}$ (iD)

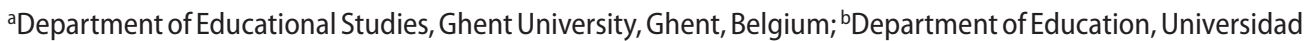 \\ Andina Simón Bolívar, Quito, Ecuador
}

\begin{abstract}
Universities seek innovation by designing and implementing professional development initiatives (PDI) for their teachers. Here it is expected that teachers will apply their learning to the workplace. However, such transfer does not always occur. To address this problem, we analyse the PDI design process of 12 universities in terms of how they consider the main variables influencing transfer: intervention design, work environment, and characteristics of the learner. Qualitative data from 16 interviews suggest that programme designers tend to focus mainly on variables related to the intervention design and work environment, but struggle to address the needs of the teacher. These findings can help universities realign their focus, by emphasising teacher-centred PDI to improve the transfer of learning.
\end{abstract}

\section{KEYWORDS}

Professional development initiatives; higher education; teacher-centred professional development; faculty development; transfer of learning

\section{Introduction}

There are several terms used internationally to define the professionalisation of university teachers: continuing professional development, academic development, staff development, instructional training, among others (De Rijdt, Dochy, Bamelis, \& van der Vleuten, 2016). While each of these terms refer to aspects of teacher professionalisation, they do have subtle differences. This study focuses on professional development initiatives (PDI), a term describing the formal activities explicitly designed and implemented by universities to improve the knowledge and skills of their teachers (Merchie, Tuytens, Devos, \& Vanderlinde, 2016).

Research indicates that there has been improvement in the quality of education through the implementation of PDI (Popovic \& Fisher, 2016). Accordingly, universities design and implement PDI for their teachers to enhance innovation and bring about reform (Baume \& Baume, 2013). Following this scheme, university teachers are expected to participate in PDI to improve their skills and apply their learning to the workplace (De Rijdt et al., 2016). Researchers from various disciplines use the terms 'transfer of learning' or'transfer of training' to refer to the successful application of the knowledge acquired in training. As these terms 
have somewhat different meanings, in this paper we use the term 'transfer' to denote the application of new learning acquired in a PDI to the workplace (Gegenfurtner, 2011).

While transfer is expected, the application of learning does not always occur (Botma, Van Rensburg, Coetzee, \& Heyns, 2015). Previous research on PDI has identified a number of variables that influence transfer, commonly grouped into three clusters: design intervention, work environment, and characteristics of the learner (De Rijdt, Stes, van der Vleuten, \& Dochy, 2013). This evidence-based framework facilitates an analysis of the current state of PDI in view of transfer, i.e. whether current PDI provide optimal conditions for teachers to apply their learning to the workplace. However, research on the attention given to these variables by PDI designers is scarce. This study examines how influencing variables are included in the PDI design process in 12 universities. Data was collected by means of 16 interviews with PDI designers, i.e. university authorities in charge of the design and implementation process of PDI for their teachers. The complex process of including variables that influence transfer, particularly those related to the characteristics of the learner, is highlighted. Besides identifying areas of improvement in transfer, this study emphasises the increasing need for a teacher-centred PDI, i.e. programmes that consider the characteristics of the learner.

\section{Teacher-centred professional development initiatives}

Given the abundant research indicating the benefits of student-centred learning at all levels of education, it seems appropriate for PDI design to consider the teacher-as-a-student. Due to the central role of the teacher in both settings (PDI and transfer) certain principles need to be considered. Firstly, when teachers participate in a PDI they become 'learners'; they need to construe meaning before applying their learning to a new context (Lobato, 2012). Secondly, transfer is not an automatic response to PDI, but a complex dynamic process centred on the teacher (Larsen-Freeman, 2013). The teacher is the one who ultimately decides whether to apply the learning to the workplace. In this sense the teacher is one of the most influencing factors in transfer. Thus, to foster transfer it is vital to place the teacher at the centre of PDI.

Current design processes of PDI are increasingly incorporating teacher-centred models as an alternative to the traditional vertical model, consisting of the transmission of information by an expert. Effective practices, such as that of Cho and Rathbun (2013), propose the use of online environments and problem-based learning to design teacher-centred PDI. Evans' (2014) analysis of professional development presents a 'teacher-centred leadership approach,' calling for leaders of PDI to consider teachers as individuals fostering the various dimensions of change that occur during training: attitudinal, intellectual, and behavioural. To improve transfer, some models present design principles for educators based on the activation of existing knowledge, engagement with new information, demonstration of competence, and application in real-world practice (Botma et al., 2015). Despite current efforts, research on how PDI models can facilitate transfer and the same time empower teachers through the inclusion of their individual characteristics is lacking (Dreer, Dietrich, \& Kracke, 2017). Indeed, De Rijdt et al. (2016) found that teachers still perceive the'management model' to be prevalent in the application of PDI, namely, a top-down model designed by institutional authorities. If transfer is one of the aims of PDI, research needs to clarify how to place the teacher at the centre. 


\section{Transfer and its influencing variables}

As noted above, transfer should not be reduced to a mere transmission or 'passing over' of information from training to the workplace. Instead, transfer should be considered as a dynamic process where the learner - in this case the teacher - transforms the knowledge acquired in a PDI before implementing it in a different setting (Larsen-Freeman, 2013). For this reason, transfer is an essential area of study in education due to its impact on teacher learning and educational improvement (Aelterman, Vansteenkiste, Van Keer, \& Haerens, 2016; Renta Davids, Van den Bossche, Gijbels, \& Fandos Garrido, 2017). Since PDI are set up to improve the quality of education for students, teachers, and the institution, a lack of transfer is a concern to all involved (Avalos, 2011; Drew \& Klopper, 2014).

Researchers have identified numerous variables affecting transfer in higher education (see De Rijdt et al., 2013). These have been grouped into three clusters. The first cluster concerns 'intervention design,' which encompasses factors that relate to the format or structure of a PDI, such as content relevance, active learning, technological support, and learning climate. The second cluster concerns the 'work environment,' which comprises factors related to the work-setting, such as a strategic link, organisational support, accountability, and supervisory support. The third cluster refers to 'characteristics of the learner,' which includes the various aspects directly related to the teacher, such as motivation, career planning, cognitive ability, among others. Nevertheless, while the above mentioned variables can be categorised into separate clusters, the variable that is common to all in terms of its influence on the application of learning is the teacher (Hattie, 2009).

In addition to identifying the main variables influencing transfer, it is important to examine how these variables are addressed by designers. This will highlight areas for improvement in the design of PDI, especially in view of supporting the teacher during the transfer process.

\section{Research design}

Building on previous research on the variables influencing transfer (Blume, Ford, Baldwin, \& Huang, 2010; De Rijdt et al., 2013), this study addresses the following question: To what extent does the PDI design process in higher education consider the variables influencing transfer?

This question is posited in order to address the current focus of the design process and the challenges to designing teacher-centred PDI. In addressing this question, we conducted semi-structured interviews with PDI designers from Ecuadorian universities in charge of the design/implementation process of PDI for their teachers. Respondents were asked to indicate how they consider the three clusters of variables that influence transfer in the design process of PDI.

\section{Sample}

Ecuadorian universities were purposefully selected on the basis of their academic rank and geographical location. For academic rank, we used the criteria established by the local government agency in charge of evaluating institutions of higher education: The Council of Evaluation, Accreditation, and Quality Assurance of Higher Education (CEAACES) of Ecuador. 
According to pre-established indicators, Ecuadorian universities are evaluated by CEAACES and placed in a category ranging from the highest (A), to the lowest (D). At the time of data collection, five universities were positioned in Category $A$ and 22 universities in Category $B$. The initial sample consisted of ten universities from groups $A$ and $B$, geographically located in the three main cities of Quito, Guayaquil, and Cuenca. A university from Category D was included, representing a vulnerable area of the country, as well as one major university from Category $C$ due to its historical importance and size. In total, the sample consisted of 12 universities from 4 cities: 5 private and 7 public universities. At least one PDI designer was interviewed in each university. In total 16 interviews with PDI designers were set up.

\section{Procedure and data analysis}

University authorities gave permission for us to set up face-to-face interviews with the PDI designers, and each interviewee gave a written consent. The first author carried out one-hour interviews, guaranteeing anonymity to all participants and the institutions. Interviews were recorded and transcribed. Additionally, the researcher took notes during the interviews (Cresswell, 2003).

QSR NVivo 11 was used to systematically analyse the transcripts, following indicators about the main variables influencing transfer. Each interview was considered as an individual case representing a university. We considered each individual reply to an interview question as a unit of analysis. Replies to questions were considered as holistic units that could incorporate multiple indicators. To determine reliability, the coding was repeated for $15 \%$ of the data (randomly selected) by an independent coder unfamiliar with the study. This resulted in an inter-rater reliability of $80 \%$, meeting the standards of Rust and Cooil (1994). Furthermore, the results of this study were shared with the respondents to include their feedback.

\section{Results}

The results indicate that current PDI designers in Ecuadorian universities do consider the variables mentioned in the literature. The overall number of indicators relating to each cluster are as follows: 'intervention design' $=396$; 'work environment' $=243$; and 'characteristics of the learner' $=123$. Further analysis was carried out to gain a deeper understanding of their nature.

An in-depth analysis of participants' responses shows the different ways that current PDI design processes address the variables of transfer. Below we group these findings in line with the three clusters together with themes emerging in the literature (De Rijdt et al., 2013).

\section{Intervention design}

Designers mostly focus on the design process of the PDI. Due to the vast number of themes and indicators found in this section, we present only those directly related to transfer.

\section{Needs analysis (universities: 10, indicators: 39 )}

Respondents mentioned that a needs analysis is common practice. However, examples of these were limited to (a) building on PDI evaluation questionnaires, and (b) teaching 
performance evaluations. The latter is a process linked to evaluation cycles suggesting that participants attend PDI to improve their performance:

U11: we already have the needs that the teacher selected in the survey, it measures what they want. Then, we begin to structure [the PDI].

The needs analysis was restricted to defining the content and providing an evaluation at the end of a course, paying little attention to methodologies, timing, or transfer itself. It seems that an established needs analysis that allows the teacher to actively participate in the PDI design process is one of the biggest challenges faced by designers. As one respondent suggested: 'we should also make a study to determine the training needs that teachers present.'

\section{Course content (universities: 11, indicators: 89)}

Regarding the process of choosing the content, our findings suggest that the dominant procedure follows a top-down structure, i.e. interventions are defined by university authorities. University teachers play a minor role in its design. As one respondent mentioned, 'the Academic Council (vice-rector, vice-deans) approves the training programmes for the faculty.'

However, in one university attempts to directly involve university teachers was found:

U8: The [schools] demand some elements. The professors in the area discuss and say 'look, we are weak in this and we need to work on these areas.' They demand certain aspects from the training. They come to us, and we on the other hand, work with the [school] of education to articulate the training proposal.

It is common practice for the PDI units to propose the training content to their faculties. Likewise, the faculties may propose a different content. Due to the diversity in training needs among disciplines, the latter is encouraged:

U9: The school tells us 'we need a workshop'...they suggest with whom we do the training, who to contact, and we support the process of developing the course, the definition of criteria for evaluation and the approval of the seminaries.

Also, university teachers are provided with a 'menu, often structured into two clusters: pedagogical content and scientific research. We provide an example on the design process of a private university:

U3: First there is a three-level process. The first criterion in choosing the content is the need of the State. That is, they consider the policies dictated by the State. The second is the need of the companies. Companies express their training needs to the university. And the third criterion is the needs of the institution.

Building on the former, PDI designers consult educational experts to choose the content. Once experts define the content, they start to organise the PDI.

During the design process there appears to be little direct involvement of university teachers in choosing the training content. This highlights the difficult challenge of satisfying the needs of all stakeholders, such as students, teachers, university authorities, and the government. The results from this cluster analysis suggest that a significant amount of effort goes into logistics and the organisation of PDI. 


\section{Work environment}

\section{Accountability (universities: 10; indicators: 32)}

Respondents expressed the importance of holding university teachers responsible for applying what they learnt. For example, university teachers are held responsible for sharing their training with their peers. This strategy can help teachers consolidate their learning and foster transfer. Nonetheless, it is not clear how the learning is transferred to the classroom. The inclusion of this variable seems limited to strategies that foster participation in PDI but not necessarily that of transfer. External factors, such as accreditation, tenure-track and evaluation, were salient factors in holding teachers responsible for their participation in PDI. Surprisingly, no particular strategy around transfer was mentioned, as the following fragment suggests:

U1: The certificate helps teachers in their reports, evaluation of the degree programme, and more... if the teacher applies the new learning, that's the teacher's decision...that is why they participate [in PDI], right?

\section{Strategic link (universities: 11; indicators: 111)}

The majority of indicators in the cluster on work environment referred to the way PDI respond to organisational goals and strategies. Respondents mentioned that the implementation of PDI strengthens the institution in areas such as institutional values, pedagogy, entrepreneurship, and accreditation processes. For example, one respondent mentioned that the institution 'trains their teachers on the design of exam questions, so that the students will be better prepared to respond to the state-tests questions.' In order to practice their professions, students from some disciplines, e.g. medicine, must pass a state-test after graduating. The Ecuadorian accreditation process for universities takes into account the number of students who successfully complete their studies, expecting a low number of drop-outs. This external factor seems to influence their strategic planning.

\section{Transfer climate (universities: 9; indicators: 65)}

The literature on transfer does not specifically list educational reform as an influencing variable. Nonetheless, we found evidence of its influence on the transfer climate. The two most influential elements of reform are: (a) requiring university teachers to fulfil hours of training for tenure purposes, and (b) institutional accreditation processes. The influence of these elements is evident when choosing the content of PDI, thus affecting transfer. For example, one respondent mentioned that they even invite government experts to participate in the design of the PDI expecting that the learning applied will assist in fulfilling institutional requirements:

U3: Educational policies present clear objectives for the country, hence we [the universities] need to follow those objectives.

\section{Organisational support (universities: 10; indicators: 35 )}

Respondents explained that supporting their teachers in the acquisition of doctoral degrees and research projects improves the quality of their institutions. Support was limited to scholarships, research grants and time allocated to do research. We found no indicators reflecting a follow-up process after the conclusion of a PDI that may foster transfer. Once a teacher participates in a PDI'we give them a certificate and then it becomes the teacher's problem.' 
Most commonly, a PDI concludes by handing out a certificate. This is a requirement of tenure.

\section{Characteristics of the learner}

\section{Career planning (universities: 3, indicators: 4)}

Career planning was mentioned as an incentive to foster participation in PDI, given that university teachers in Ecuador need to fulfil hours of training for tenure purposes. Ecuadorian policy requires university teachers to participate in PDI for a minimum of 224 hours to secure full-professorship (Consejo de Educación Superior, 2017). Therefore, the influence of this incentive is visible in the design of PDI:

U3: [the law] tells us that we need a certificate of minimum forty hours, this motivates people because this helps in their tenure track.

\section{Perceived utility (university: 5 , indicators: 10)}

Respondents expressed concerns about helping university teachers understand the importance of attending PDI. According to one respondent, university teachers prefer not to be 'outside their comfort zone.'This is often reflected by the low numbers of participants attending PDI:

U1: It is always very difficult [to deal] with teachers. We could have had twenty participants, but we had only eight. These are long courses and they must give up their time. Still they are not conscious of the need that they have to continue [a PDI].

\section{Teaching ability (universities 6: indicators: 15)}

Teaching ability seems to influence the design of PDI. Respondents suggest that PDI should be designed to remedy shortcomings in ability for areas such as ICT, scientific research, and teaching methodologies. The latter is a major concern for the designers:

U10: here we do not have teachers that are well prepared in [teaching] methodologies.

\section{Teacher's experience (universities: 11, indicators: 44)}

Designers reported they do consider university teachers' work experience. There is a focus on those with less than two years of experience. Universities mainly encourage PDI for those starting in a tenure-track position, rather than experienced faculty members, as the former seem 'much easier to manage.' Institutional policies range from free registration for PDI, to setting up courses specifically designed for new university teachers:

U10: Since they are new, they are eager to receive [PDI] because they do not have a teaching profile. They are professionals in their field. Their master's degrees are from an area of their academic fields, but we motivate them to grow in their career [as teachers].

On the other hand, designers expressed having difficulty involving experienced teachers:

U1: Of course, they are the ones that need it [PDI] the most ... they are the ones that show the most resistance. 
Teacher qualifications (universities: 7, indicators: 31 )

Respondents emphasised the determining factor of teacher qualification. The following themes emerged from the analysis: pedagogical abilities, teacher behaviour and attitudes.

One respondent mentioned that students'prefer excellent teachers rather than excellent professionals.'Thus, being a top academic researcher is not sufficient:'professors hold a PhD, but they lack tools to teach.' Students demand professionals that know how to teach. PDI designers consider it their duty to develop the pedagogical competences of their teachers: 'we want to strengthen their continuous education in areas of pedagogy' rather than in areas of academic content, since 'they will look for their own preparation.' The lack of teacher education in university teachers is clearly a priority:

U4: Sure, they are experts; expert engineers, expert medical doctors, expert mathematicians, but they do not really have continuity and never had, surely never had... pedagogical training.

Interviewees are aware that implementing PDI is not enough. A course may be insufficient to counter a lack of pedagogical instruction. Interviewees stressed the need for a 'process of professional formation... as a teacher' in university education.

PDI designers do understand this challenge and refer to the 'students' voice' as an information source to identify areas of improvement. They list student complaints about the behaviour and attitude of some university teachers who 'do not arrive on time, do not give the grades on time, leave class before the scheduled time ...' Designers expressed concern about 'the way they treat the student and respect the student'.

\section{Motivation (universities: 3 ; indicators: 17)}

The few designers that referred to motivation mainly linked this to participation in PDI, specifically noting tenure-track as one of the main motivating factors. We found no evidence of initiatives fostering 'motivation to transfer' in the PDI design.

Compared to the other two clusters of influencing variables, this cluster received the least consideration by designers. The fundamental purpose of PDI seems to address the pedagogical void in the preparation of university teachers, particularly the young teachers that seem to show acceptance and openness to change through PDI.

\section{Discussion}

This study investigated the design process of PDI in universities through what research considers to be the most influencing variables of transfer: intervention design, work environment, and characteristics of the learner. This study's contribution to the literature is based on an analysis of the current state of PDI and their suitability for transfer. By implementing an evidence-based framework we investigated whether current PDI designers consider variables that influence transfer. This study also highlights the challenges faced by designers in incorporating the three clusters of variables in their work.

Our findings show the prominent consideration given to the operational aspects of PDI. While organisation is key, transfer may require a wider focus that is specially related to teacher characteristics. This is in line with previous research suggesting that studies on transfer pay more attention to variables related to intervention design (De Rijdt et al., 2013). Designers struggle to actively involve university teachers in the design process, which is an important 
influencing factor in their professional satisfaction (Starkey et al., 2009). Designers' attempts to involve participants were limited to needs analyses based on evaluation procedures of the PDI itself, and not its impact on learning or transfer. We found few indicators focusing on teaching methodologies that aim at transfer, such as hands-on practice workshops or active learning.

Regarding the work environment, this study found that designers conceive the professionalisation of university teachers as crucial for institutional growth. Accountability, strategic link, transfer climate, and organisational support were the variables included in the design of PDI. For example, university teachers are considered to be responsible for transfer by disseminating their learning to peers. Nonetheless, designers require strategies to establish a much needed support climate to foster knowledge and transfer (Song, Bae, Park, \& Kim, 2013). In the Ecuadorian context, educational reform seems to influence the decisions of designers and consequently the design of PDI. This diverts the focus from the university teacher to the fulfilment of institutional requirements.

An important finding of this study is the difficulty expressed by designers to create teacher-centred PDI. Institutional and governmental requirements seem to significantly influence the design process. This raises concern, since overlooking learner characteristics may hinder transfer (Gorozidis \& Papaioannou, 2014). Although current PDI models increasingly focus on the teacher, our study suggests that the design of teacher-centred models needs further attention, i.e. to shift PDI design based on the transmission of information by experts to a design that includes systematic institutional support for university teachers throughout their learning and transfer process (van der Sluis, Burden, \& Huet, 2017).

\section{Implications and limitations}

A critical finding of this study is the absence of motivational variables in the design considerations of PDI. Among the most salient influencing variables of transfer (belonging to the characteristics of the learner) is motivation (De Rijdt et al., 2013). Variables such as motivation to transfer, motivation to learn, and motivation to participate have been found to improve transfer (Segers \& Gegenfurtner, 2013). Including motivational theories into the design of PDI might comprise a promising and innovative model for implementing PDI in higher education, focusing on motivating the teachers instead of coercing them to fulfil institutional requirements. This requires PDI designers to adopt a holistic and theory-based approach when designing PDI in view of supporting the university teacher in the transfer process.

This study is limited by its focus on the perspective of PDI designers and not on other stakeholders. Further studies may incorporate university teachers and students, analysing the extent that PDI improves the adoption of specific teaching and learning processes and their effect on student performance. Future research could also focus on the analysis of actual on-campus implementations.

\section{Conclusion}

The present study fills a gap in the literature by analysing the nature of current PDI characteristics and their link with transfer. As suggested by the results of this study, not enough consideration is given to the learner characteristics of the university teacher. Consequently, there is a need for theoretical frameworks that highlight the importance of the learner in 
the design process of PDI, despite external pressure from institutional or governmental requirements.

\section{Disclosure statement}

No potential conflict of interest was reported by the authors.

\section{Funding}

This work was supported by Fondos de Investigacion Universidad Andina Simon Bolivar-Ecuador [grant number P215].

\section{Notes on contributors}

Christian Jaramillo-Baquerizo is the Director of the Department of Education at Universidad Andina Simon Bolivar-Ecuador. He is a PhD candidate at the Department of Educational Studies, Ghent University, Belgium. His research interest is on teacher professional development and transfer of learning.

Martin Valcke is a Full Professor at Ghent University, Belgium and Head of the Department of Educational Studies. His actual field of research focuses on the innovation of Higher Education and the integrated use of ICT.

Ruben Vanderlinde is a professor at the Department of Educational Studies at Ghent University, Belgium. His research interests are in the field of educational innovation, teacher induction, teacher training and professionalisation, and the integration of ICT in education.

\section{ORCID}

Christian Jaramillo-Baquerizo (iD http://orcid.org/0000-0002-8081-1318

Martin Valcke (iD http://orcid.org/0000-0001-9544-4197

Ruben Vanderlinde (D) http://orcid.org/0000-0002-4912-3410

\section{References}

Aelterman, N., Vansteenkiste, M., Van Keer, H., \& Haerens, L. (2016). Changing teachers'beliefs regarding autonomy support and structure: The role of experienced psychological need satisfaction in teacher training. Psychology of Sport and Exercise, 23, 64-72. doi:10.1016/j.psychsport.2015.10.007

Avalos, B. (2011). Teacher professional development in Teaching and Teacher Education over ten years. Teaching and Teacher Education, 27, 10-20. doi:10.1016/j.tate.2010.08.007

Baume, C., \& Baume, D. (2013). The birth and death of academic development? Innovations in Education and Teaching International, 50, 384-387. doi:10.1080/14703297.2013.839391

Blume, B. D., Ford, J. K., Baldwin, T. T., \& Huang, J. L. (2010). Transfer of training: A meta-analytic review. Journal of Management, 36, 1065-1105. doi:10.1177/0149206309352880

Botma, Y., Van Rensburg, G. H., Coetzee, I. M., \& Heyns, T. (2015). A conceptual framework for educational design at modular level to promote transfer of learning. Innovations in Education and Teaching International, 52, 499-509. doi:10.1080/14703297.2013.866051

Cho, M.-H., \& Rathbun, G. (2013). Implementing teacher-centred online teacher professional development (OTPD) programme in higher education: A case study. Innovations in Education and Teaching International, 50, 144-156. doi:10.1080/14703297.2012.760868

Consejo de Educación Superior. (2017). Reglamento de Régimen Académico, Pub. L. No. CES-SG2017-R-019 (2017). Ecuador. 
Cresswell, J.W. (2003). Qualitative, quantitative, and mixed methods approaches (3. ed., [N). Los Angeles, CA: Sage.

De Rijdt, C., Stes, A., van der Vleuten, C., \& Dochy, F. (2013). Influencing variables and moderators of transfer of learning to the workplace within the area of staff development in higher education: Research review. Educational Research Review, 8, 48-74. doi:10.1016/j.edurev.2012.05.007

De Rijdt, C., Dochy, F., Bamelis, S., \& van der Vleuten, C. (2016). Classification of staff development programmes and effects perceived by teachers. Innovations in Education and Teaching International, 53, 179-190. doi:10.1080/14703297.2014.916543

Dreer, B., Dietrich, J., \& Kracke, B. (2017). From in-service teacher development to school improvement: Factors of learning transfer in teacher education. Teacher Development, 21, 208-224. doi:10.1080/ 13664530.2016 .1224774

Drew, S., \& Klopper, C. (2014). Evaluating faculty pedagogic practices to inform strategic academic professional development: A case of cases. Higher Education, 67, 349-367. doi:10.1007/s10734-0139657-1

Evans, L. (2014). Leadership for professional development and learning: Enhancing our understanding of how teachers develop. Cambridge Journal of Education, 44, 179-198. doi:10.1080/030576 4X.2013.860083

Gegenfurtner, A. (2011). Motivation and transfer in professional training: A meta-analysis of the moderating effects of knowledge type, instruction, and assessment conditions. Educational Research Review, 6, 153-168. doi:10.1016/j.edurev.2011.04.001

Gorozidis, G., \& Papaioannou, A. G. (2014). Teachers' motivation to participate in training and to implement innovations. Teaching and Teacher Education, 39, 1-11. doi:10.1016/j.tate.2013.12.001

Hattie, J. (2009). Visible learning. A synthetis of over 800 meta-analyses relating to achievement. (Vol. 53). New York, NY: Routledge.

Larsen-Freeman, D. (2013). Transfer of learning transformed. Language Learning, 63(SUPPL. 1), 107-129. doi:10.1111/j.1467-9922.2012.00740.x

Lobato, J. (2012). The actor-oriented transfer perspective and its contributions to educational research and practice. Educational Psychologist, 47, 232-247. doi:10.1080/00461520.2012.693353

Merchie, E., Tuytens, M., Devos, G., \& Vanderlinde, R. (2016). Evaluating teachers' professional development initiatives: Towards an extended evaluative framework. Research Papers in Education, 1522(January), 1-26. doi:10.1080/02671522.2016.1271003

Popovic, C., \& Fisher, E. (2016). Reflections on a professional development course for educational developers. Innovations in Education and Teaching International, 53, 487-496. doi:10.1080/14703 297.2015.1121160

Renta Davids, A. I., Van den Bossche, P., Gijbels, D., \& Fandos Garrido, M. (2017). The impact of individual, educational, and workplace factors on the transfer of school-based learning into the workplace. Vocations and Learning, 10, 275-306. doi:10.1007/s12186-016-9168-1

Rust, R. T., \& Cooil, B. (1994). Reliability measures for qualitative data: Theory and implications. Journal of Marketing Research, 31, 1-14. doi:10.2307/3151942

Segers, M., \& Gegenfurtner, A. (2013). Transfer of training: New conceptualizations through integrated research perspectives. Educational Research Review, 8, 1-4. doi:10.1016/j.edurev.2012.11.007

van der Sluis, H., Burden, P., \& Huet, I. (2017). Retrospection and reflection: The emerging influence of an institutional professional recognition scheme on professional development and academic practice in a UK university. Innovations in Education and Teaching International, 54, 126-134. doi:10 $.1080 / 14703297.2016 .1273790$

Song, J. H., Bae, S. H., Park, S., \& Kim, H. K. (2013). Influential factors for knowledge creation practices of CTE teachers: Mutual impact of perceived school support, transformational leadership, and work engagement. Asia Pacific Education Review, 14, 467-482. doi:10.1007/s12564-013-9283-8

Starkey, L., Yates, A., Meyer, L. H., Hall, C., Taylor, M., Stevens, S., \&Toia, R. (2009). Professional development design: Embedding educational reform in New Zealand. Teaching and Teacher Education, 25, 181-189. doi:10.1016/j.tate.2008.08.007 